\title{
Self-Compassion in Relation to Self-Esteem, Self-Efficacy and Demographical Aspects ${ }^{1}$
}

\author{
Luciana Karine de Souza ${ }^{2}$ \\ Universidade Federal do Rio Grande do Sul, \\ Porto Alegre-RS, Brazil
}

\author{
Claudio Simon Hutz \\ Universidade Federal do Rio Grande do Sul, \\ Porto Alegre-RS, Brazil
}

\begin{abstract}
This study investigated relationships between self-compassion, self-efficacy, and self-esteem, as well as age and sex differences and other sociodemographic variables in relation to self-compassion. Four-hundred and thirty-two Brazilian adults ( $50 \%$ women) from nearly all country states participated in the study filling out a sociodemographic survey and three scales: self-compassion, self-efficacy, and self-esteem. Comparisons of means between self-compassion and pairs of groups designed by sociodemographic data showed higher self-compassion in men, people aged from 31 to 66 years-old, not under psychiatric medication, without a job, and with children. Results also showed that self-compassion is highly correlated with self-esteem and self-efficacy. We highlight that results are sample dependent and further studies on self-compassion need to be conducted in Brazil.
\end{abstract}

Keywords: self-compassion, self-esteem, self-efficacy

\section{Autocompaixão e Suas Relações com Autoestima, Autoeficácia e Aspectos Sociodemográficos}

\begin{abstract}
Resumo: O presente estudo teve por objetivo investigar as relações entre autocompaixão, autoestima e autoeficácia e diferenças de sexo, idade e de outras variáveis sociodemográficas na autocompaixão. Participaram 432 adultos ( $50 \%$ mulheres), de 24 estados brasileiros, preenchendo dados sociodemográficos e um conjunto de três escalas: autocompaixão, autoestima e autoeficácia. Comparações de médias da autocompaixão por grupos compostos a partir dos dados sociodemográficos permitiram observar maior autocompaixão em: homens, com idade entre 31 e 66 anos, sem uso de medicação psiquiátrica, sem atividade remunerada e com filhos. Os resultados também mostraram que autocompaixão apresenta correlações elevadas com autoeficácia e autoestima. Salienta-se que os resultados são atinentes a esta amostra e que mais estudos precisam ser conduzidos no Brasil sobre autocompaixão.
\end{abstract}

Palavras-chave: autocompaixão, autoestima, autoeficácia

\section{Autocompasión y Sus Relaciones con Autoestima, Autoeficacia y Aspectos Sociodemográficos}

\begin{abstract}
Resumen: El presente trabajo investigó las relaciones entre autocompasión, autoestima y autoeficacia y las diferencias entre sexo, edad y otras variables sociodemográficas en la autocompasión. Participaron 432 adultos (50\% mujeres) de 24 Estados brasileños, llenando datos sociodemográficos y un conjunto de tres escalas: autocompasión, autoestima y autoeficacia. Comparaciones de promedios de la autocompasión en grupos compuestos a partir de los datos sociodemográficos, permitieron observar mayor autocompasión en: hombres con edad entre 31 y 66 años, sin uso de medicamento psiquiátrico, sin actividad remunerada y con hijos. Los resultados también mostraron que autocompasión presenta correlaciones elevadas con autoeficacia y autoestima. Se resalta que los resultados son relacionados con esta muestra y que más estudios necesitan ser conducidos en Brasil, con respecto a la autocompasión.
\end{abstract}

Palabras clave: autocompasión, autoestima, autoeficacia

\footnotetext{
${ }^{1}$ Study derived from the post-doctoral research project "Adaptation and Validation of the Self-Compassion Scale", conducted by the first author, under the supervision of the second author. Acknowledgement: We would like to thank K. Neff, L. Taborda, J. Natividade, J. Rique, A. Antoniazzi, J. Sarriera, and the 2012 team of Laboratory of Measurement at Universidade Federal do Rio Grande do Sul (UFRGS). Institutional support: Psychology Department at Universidade Federal de Minas Gerais and Programa de PósGraduação em Psicologia at UFRGS.

Support: National Council for Scientific and Technological Development CNPq (Grant \# 159687/2011-0).

${ }^{2}$ Correspondence address:

Luciana Karine de Souza. Universidade Federal do Rio Grande do Sul, Programa de Pós-Graduação em Psicologia. Rua Ramiro Barcelos, 2600. CEP 90035-003. Porto Alegre-RS, Brazil. E-mail: lukarides@gmail.com
}

Self-compassion is compassion placed on the person himself. It is not self-pity, self-commiseration or selfindulgence. Medeiros and Sougey (2010) have used the expression "self-compassionate thoughts" (p. 29) to describe a certain cognitive distortion typical of depressed patients. Nevertheless, an expression such as "self-pity thoughts" (pensamentos de autopiedade) would better describe this attitude. Self-compassion does not mean that.

Neff (2003a), inspired by a Buddhist concept of selfcompassion (SC), pioneered in both providing an operational definition and a measure for SC. While compassion entails 
openness and allowing oneself to be in touch with someone else's suffering in such a way that one wants that suffering to be relieved, SC is a self-understanding attitude which requires to allow oneself to be in touch with one's own suffering, manifest openness towards it while seeking not to turn away or to be disconnected from it. This openness should lead to the wish to assuage the suffering, to heal oneself with kindness, without judgments, through the understanding of one's sorrows, inadequacies and failures. In this way these experiences will, through SC, be recognized as part of a broad human experience. Furthermore, feelings of SC, when genuine and complete, awaken one's desire for one's health and well-being (Neff, 2003a, 2003b).

SC has six elements: self-kindness, self-judgment, isolation, common humanity, over-identification, and mindfulness. Self-kindness means applying kindness and good-will towards oneself, avoiding harsh judgments and self-criticism. Common humanity implies one understands one's own experiences as part of a wider human experience, refraining from grasping them as separate, isolating them. Mindfulness, on the other hand, is to maintain a balanced awareness of painful feelings and thoughts, instead of overidentifying with or denying them (Neff, 2003a).

These elements work together in the manifestation of SC. At the outset, the first step for SC to develop is a balanced mental state originated in mindfulness, which allows for a more universal understanding of suffering, and for the emergence of self-kindness; moreover, this mental state reduces self-criticism and increases self-understanding. The balanced point-of-view that comes through mindfulness hinders self-centeredness, which leads to the idea of isolation within the experience of sufferings, errors and failures. It fosters feelings of connection through awareness of common humanity in the context of a universal understanding of negative experiences. Also both self-kindness and awareness of common humanity help reducing harsh self-criticism and severe judgment directed towards oneself, allowing for the emergence of self-acceptance, which then reduces the emotional load concomitant with the experience of suffering, and thus facilitating the maintenance of a well-balanced consciousness between thoughts and feelings (Neff, 2003a).

Self-pity, on the other hand, distances one from others, engulfing one in one's own problems. In doing that, the subject disregards that others may face similar or even more severe difficulties, allowing one to be overcome by negative feelings. Thus the experience of suffering is exaggerated, leading to an over-identification with it. In contrast to that, $\mathrm{SC}$ allows for the recognition of relatedness between humans and a sense of shared experiences (both good and bad). In this way over-identification with suffering is avoided, reducing egocentrism and promoting a sense of interconnectedness with others (Neff, 2003a, 2003b).

Neff (2003b) has created and validated the SelfCompassion Scale (SCS). The author has found significant negative correlations with self-criticism, and positive ones with social connection; with good performance in a testretest within a three week interval, showing correlations between .80 and .93 ; and a moderate correlation $(r=.59)$ with Rosenberg's Self-Esteem Scale (RSES). Comparisons with anger, anxiety and life satisfaction have confirmed SCS ability to predict aspects of psychological health. Finally, Neff (2003b) has, in the same research, investigated 43 practicing Buddhists that, compared to college students, showed significantly more SC. Detailed analysis indicated that Buddhist practice wielded a greater effect on SC than on self-esteem. A significant positive correlation was found between SCS scores and how long Buddhism had been practiced. SCS was adapted and validated for use in Brazil by Souza and Hutz (in press), and named Escala de Autocompaixão (EAC). The 26 items on the original scale were maintained and internal consistency was .92 .

A search for self-compassion on the title of English language peer-reviewed articles published over the last 10 years, and available on Portal Periódicos CAPES, results in almost 100 studies on SC, though none of them with a Brazilian sample. Studies correlate SC (almost all using SCS) with constructs such as optimism, hope, subjective well-being, empathy, resiliency, body image, stress, coping, homesickness, academic failure, and depression.

As the article compilation showed, many aspects are suitable for analysis with SC. It seems pertinent to ask, for example, if there are differences between SC in men and women, or between teenagers, adults and the elderly. What follows is a summary of available studies that deal with different age and gender aspects, as they relate to SC.

\section{Self-Compassion and Age and Gender Differences}

Neff (2003b) found significantly lower SC scores on women. Women scored higher than men in self-criticism, isolation and over-identification, and had lower mindfulness scores. On the Buddhist practitioner's sample, however, the absence of gender differences was an indication for the author that such practice fosters mental health in both men and women. Neff, Rude and Kirkpatrick (2007) and Iskender (2009) have failed to detect SC gender differences. However, Neff and McGehee (2010), while comparing adolescents and adults, did not found SC gender differences related in the former, while detecting lower SC in adult women. Research results suggest $\mathrm{SC}$ gender differences remain an open issue.

On the topic of age differences, Neff (2003a, 2009) resorts to Elkind (1967) to argue SC is challenging for teenagers. According to the latter, at this stage in life the individual is immersed in self-reflections, self-evaluations and comparisons with expected social standards. In his concept of teenage egocentrism, the mechanisms of personal fable (the certainty that what passes happens only to the individual and nobody else) and imaginary audience (constant sensation of being in a stage with an audience, watching) contribute to this self-immersions, as well as a heighten self-monitoring of magnified defects and imperfections. These cognitive distortions contribute to the sudden changes of humor teenagers experience in a single day. In this sense, teenage egocentrism would empower isolation, self-criticism and over-identification - three elements of SC.

Neff and McGehee (2010), in a study that compared teenagers and young adults, did not find significant SC 
differences related to age. Neither such differences were found by Neff e Pommier (2013), in a research with college students and adults that were not enrolled in higher education. The issue of age therefore also still needs to be investigated.

$\mathrm{SC}$ is a psychological health construct that seeks to contribute for the understanding of how the subject sees herself and deals with herself when faced with his own life's difficulties and sufferings. It seeks to show how the subject evaluates herself when confronted with mistakes and failures. Self-esteem is another concept related to the way people value themselves in relation to others, and how they evaluate their lives. In the next section we discuss the concept of selfesteem in contrast to SC.

\section{Self-Compassion Versus Self-Esteem in Evaluating a Healthy Attitude}

Hewitt (2005) states self-esteem as culturally based, originating from "a culture that nourishes a belief in the importance of the individual self even while making the self problematic" (p. 135) - the US culture. People follow social expectations in order to be accepted, and thus increase their self-esteem; they develop close relationships with those who evaluate them in a positive light; in order to increase their self-efficacy they engage in tasks in which they believe they can be successful. This bias, which continuously serves the self, protects self-esteem, allowing people to receive credit for their successes and blame others for failures.

Neff (2003a, 2003b) develops four arguments against self-esteem. First, due to its change-resistant character, it seems difficult for self-esteem to be increased. Second, excessive emphasis on self-esteem can lead to narcissism, self-absorption, absence of care/concern towards others, distorted self-perception and egocentrism. In third place, the wish to increase self-esteem can, on the other hand, lead one to seek out the worst in others so that one may positively stand out in contrast. The fourth argument comes from research showing positive association between high selfesteem and xenophobia: an inflated sense of self-esteem can lead to aggression and violence against those perceived as a threat. In bullying, for example, the aggressor acts that way in order to feel good (Neff, 2009).

With SC it is not necessary to resort to social comparison for self-acceptance, nor to run the risk of creating numerous or unreal expectations in an effort to get approval or reinforcement - which are all possibilities in self-esteem (Neff, 2003a, 2003b). To accept one's own mistakes and failures, to bestow kindness upon oneself, to balance thoughts and feelings over experienced suffering and to recognize oneself as a member of a human community (fallible and able to learn through errors and sorrows) allows for an accurate view of experiences and subjective states, a realist perspective over difficulties, faults and inadequacies, as well as over potentialities for change and the pursuit of happiness. Indeed, considering these points, it appears that promoting $\mathrm{SC}$ is more desirable than increasing self-esteem.

While working on the validation for the SCS, Neff (2003b) ascertained a significant positive correlation $(r=$
.59) between RSES and SCS, suggesting that they are similar constructs, with distinctions. The result was also interpreted as evidence that we should expect self-compassionate people to have a greater sense of self-worth in contrast to those who disallow themselves to err, believe their own suffering is unique, and over-identify with their own feelings - that is, people with low SC. Significant positive correlations were found between self-esteem and narcissism, while non-significant positive ones were found between narcissism and SC.

According to Leary, Tate, Adams, Allen and Hancock (2007), "when people high in self-esteem encounter negative life events, they sometimes engage in self-serving biases (...), presumably because reactions help to make them feel better about themselves" (p. 902). This defensiveness contributes to the argument that $\mathrm{SC}$ and self-esteem engender different processes.

Neff and Vonk (2009) compared three instruments of self-esteem (global, contingent and state self-esteem) to SCS and self-worth measures, social comparison, public self-consciousness, rumination, narcissism, anger, need for cognitive closure, optimism, happiness and positive affection. SC, better than self-esteem, predicted stability of self-worth feelings; it had significant and negative association with anger, social comparison, public self-consciousness, rumination and the need for cognitive closure; and it was able to predict significant additional variances over happiness, optimism and positive affection, while controlling for selfesteem. Narcissism was shown to be positively associated with self-esteem, but not to SC, as in Neff (2003b).

According to Neff (2011), SC "is available precisely when self-esteem fails us - when we fall flat on our face, embarrass ourselves, or otherwise come in direct contact with the imperfection of life" (p. 6). While self-esteem leads to feelings of superiority and self-confidence, SC promotes a sense of safety and protection.

Vonk and Smit (2012), in a recent study correlating SC and self-esteem, sampled 3.575 Netherlanders aged from 16 to 83 years old. The self-esteem scale created by the authors correlated significantly and positively both with RSES ( $r$ $=.86)$ and SCS $(r=.62)$. In Brazil RSES seems to be the preferred choice for research. Hutz and Zanon (2011) work pointed out that people between 20 and 30 years of age show less self-esteem than other age groups, and that men aged 16 to 19 years old present higher scores.

An important psychological construct associated with the way people think about seeking personal goals is self-efficacy. If one completely identifies with an illness one is facing (overidentification), severely criticizes one's own incapacities, even when they are transitory (self-criticism), mistreats oneself (shows no self-kindness), avoids interaction (isolation), does not think clearly or is not able to measure emotional reactions (without the balance of mindfulness), and believes to be the only one to suffer this way (no sense of common humanity), how one's self-efficacy belief can take hold?

\section{Self-Efficacy and Self-Compassion}

Self-efficacy involves beliefs held by people over the ability to achieve desired goals through their own actions 
(Bandura, 1997). It is the belief that one can achieve something through one's own resources, and in some circumstances, that one can perform the behavior that leads to the desired goal. It is influenced by attempts to control environments, observation of other people's behavior, imagining hypothetical situations, reactions and physiological states, and by other people's perspective over what we believe we can achieve. It is negatively associated with depression, anxiety and avoidance, and positively associated with self-confidence and attempts to overcome issues with drugs and food. It influences the adoption of healthy behaviors, withdrawing from harmful behaviors and the perseverance on changes made even when faced with challenges and difficulties. Self-efficacy beliefs affect physiological response to stress, and their promotion effectively helps with actions that improve health (Maddux, 2002).

Over the last 10 years there's been a perceptible increase in investigations about self-efficacy, both general and domain specific. There is works on self-efficacy on insulin management in patients with diabetes, in patients with chronic pain, and self-efficacy focused on student performance. On the topic of general self-efficacy, Pacico, Ferraz, and Hutz (2012) have developed a general scale of self-efficacy which shows good performance $(\mathrm{alfa}=.87)$. The most recent work on the general self-efficacy scale is Pacico et al. (2014); in it the researchers detected a .89 index of internal consistency.

Only one single study was found dealing with both SC and self-efficacy. Iskender (2009) included in his study a measure of control belief for learning. SC was evaluated with SCS and selfefficacy was analyzed by a subscale taken from an instrument of motivation strategies. The sample was composed of Turkish college students, and the reliability of the self-efficacy subscale for the population under study was .86. A positive association was found between self-efficacy, control belief for learning, self-kindness, sense of common humanity and mindfulness. On the contrary, isolation, self-criticism and over-identification were negatively associated with self-efficacy. Thus, for this author, in outlining interventions, an increase in self-efficacy would lead to decreases in social isolation, over-identification with problems, and severe self-judgment.

In discussing influences on self-efficacy, Maddux (2002) notes that successful attempts in situations in which the person is in control, and for which the result is attributed to their own efforts, increase the sense of self-efficacy. On the other hand, a perception of failure in these circumstances reduces self-efficacy. This way, it makes sense to bring a SC attitude to foreground. In such situations, the most self-compassionate individuals will be able to perceive their own failure as something also present in the lives of others, and will be able to bestow kindness on themselves when dealing with their feelings and thoughts in a balanced way. So it can be concluded that a self-compassionate attitude is relevant, so to say, for the journey of self-efficacy bearing on its increase or reduction.

\section{Seeking Relationships Between Self-Compassion, Self- Esteem, Self-Efficacy, and Sociodemographic Aspects}

As we have argued, the SC concept, though not new, is seen as a novelty within studies that focus on the subjective evaluation of processes connected to how we deal with the self. SCS, originally published in 2003, has been used in correlation to positive and negative aspects in the field of psychological health.

In following with the current discussion in the literature available, the present study sought to verify correlations between SC, self-esteem and self-efficacy, as well as an examination of aspects such as religion, experience with psychotherapy, the use of psychiatric drugs, involvement in paid occupation and having children. With respect to religion, Neff (2003b) studies with Buddhist practitioners indicated differences in SC - after all, it is a construct based on a Buddhist concept. Psychotherapy and the use of psychiatric drugs are options of treatment used on more lasting experiences of psychological suffering, and as such, can show a relationship with the SC score. Paid occupation bear on involvement in work contexts in which individuals widen their network, including hierarchies, as well as deal with successes and failures that can influence in one's wellbeing. In this way, the self-compassionate individual should be able to better deal with mistakes and faults at the work environment. On the topic of raising children, it is a significant change in someone's life, very common in the adult phase, for which the literature signals increased SC. Furthermore, parenting strategies are prone to successes and failures, hits and misses, and thus suitable for relationships with SC.

From the proposed landscape, this study has for goal the investigation of relationships between self-compassion, self-esteem and self-efficacy, gender and age differences, as well as other sociodemographic variables in self-compassion. It is an exploratory study, with both correlation and group comparison.

\section{Method}

\section{Participants}

The sample has enlisted 432 people $(50 \%$ of them women), presenting an average of $32.5(S D=11.1)$ years of age, ranging from 18 to 66 years old, from several Brazilian states. Most participants were from Minas Gerais, São Paulo, and Rio Grande do Sul; the only states with no participants were Acre, Roraima, and Piauí. As for involvement in a stable romantic relationship, $39 \%$ were married or living with someone in the equivalent of a common-law marriage and $24 \%$ were seeing someone; there were also $32 \%$ of single people, $4 \%$ of divorced or separated and $1 \%$ of widowers, that is, groups of participants with no stable romantic involvement during the data collection. To participate in the research it was necessary to be at least 18 years old, to have been born in Brazil, and to have secondary education. Participants who did not meet these criteria were excluded from the sample.

\section{Instruments}

The sociodemographic survey was customized for the research and asked for the following information: gender, age, nationality, place of birth, current city of residence, stable 
romantic relationship (married, seeing someone, divorced, etc.), religion and engagement in religious practice, going through psychotherapy, level of education, job occupation, having children, and using psychiatric drugs.

The Self-Compassion Scale (SCS) was adapted for use in Brazil by Souza and Hutz (in press) with approval by the author, Kristin Neff. The construct validation suggested all 26 original items to be retained. The internal consistency was .92. The subscales envisage SC components: self-kindness, sense of common humanity, mindfulness, over-identification, isolation, and self-criticism.

The Rosemberg's Self-Esteem Scale (RSES) used here incorporates both the versions published by Hutz and Zanon (2011) and by Hutz, Zanon and Vazquez (2014), comprised of 10 items, five of which being positive affirmations about the self, while the remaining five being negative ones. The General Self-Efficacy Scale (GSES) applied here was the Pacico et al. (2014) version, which is comprised of 30 items.

\section{Procedure}

Data collection. Data were collected through the Survey Monkey platform with a link for the research form sent by e-mail. The link first led to an informed consent agreement page that offered options to accept or decline in participating of the research. A click on the accepting link led the participant to the first page of instruments, consisting of the sociodemographic survey. The following page presented SCS, followed by RSES, and concluding with GSES. The Informed Consent Agreement was set up according to current Brazilian regulations on research with human subjects.
Data analysis. Descriptive statistics and Pearson correlations within the main scales were applied. $\mathrm{T}$ tests for group comparison were made on gender, age range (groups of 18-30 years and 31-66 years), religious practice, previous or current experience with psychotherapy, current use of psychiatric drugs, involvement in paid occupation and having children. In group comparison, the effect size was calculated according to Cohen's $d$, according to Magnusson (2014) suggested interpretation.

\section{Ethical Considerations}

This study was approved by the Research Ethics Committee of the Instituto de Psicologia at Universidade Federal do Rio Grande do Sul (UFRGS; Protocol n. 04345112.5.0000.5334).

\section{Results}

The SC average for SCS was $3.18(S D=0.70)$. Concerning self-efficacy, the sample average for GSES was $3.53(S D=0.57)$. Regarding self-esteem, the detected average for RSES was $3.04(S D=0.31)$. Table 1 presents the significant differences of SC via SCS for the following groups: women and men, age group (17-30 and 31-66), current use of psychiatric drug, paid occupation and having children. Comparisons on current or previous experience with psychotherapy and religious practice did not indicate significant differences on SC, and are thence not presented on the table.

Table 1

Mean Comparisons With the Self-Compassion Scale

\begin{tabular}{|c|c|c|c|c|}
\hline & \multicolumn{4}{|c|}{ Self-Compassion Scale } \\
\hline & $M(S D)$ & $t$ & $p$ & $d$ \\
\hline \multicolumn{5}{|l|}{ Gender } \\
\hline Women $(n=216)$ & $3.09(0.74)$ & \multirow{2}{*}{2.581} & \multirow{2}{*}{.01} & \multirow{2}{*}{.26} \\
\hline $\operatorname{Men}(n=216)$ & $3.27(0.66)$ & & & \\
\hline \multicolumn{5}{|l|}{ Age range } \\
\hline $18-30$ years $(n=228)$ & $3.05(0.66)$ & \multirow{2}{*}{-4.158} & \multirow{2}{*}{.001} & \multirow{2}{*}{.40} \\
\hline $31-66$ years $(n=204)$ & $3.33(0.72)$ & & & \\
\hline \multicolumn{5}{|l|}{ Medication use } \\
\hline Yes $(n=61)$ & $2.93(0.83)$ & \multirow{2}{*}{3.048} & \multirow{2}{*}{.002} & \multirow{2}{*}{.38} \\
\hline No $(n=371)$ & $3.22(0.67)$ & & & \\
\hline \multicolumn{5}{|l|}{ Paid occupation } \\
\hline Yes $(n=98)$ & $3.01(0.67)$ & \multirow{2}{*}{2.714} & \multirow{2}{*}{.007} & \multirow{2}{*}{.32} \\
\hline No $(n=334)$ & $3.23(0.70)$ & & & \\
\hline \multicolumn{5}{|l|}{ Offspring } \\
\hline Yes $(n=122)$ & $3.37(0.66)$ & \multirow{2}{*}{-3.673} & \multirow{2}{*}{.001} & \multirow{2}{*}{.39} \\
\hline No $(n=310)$ & $3.10(0.71)$ & & & \\
\hline
\end{tabular}

Note. $M=$ mean, $S D=$ standard deviation, $d=$ Cohen's $\mathrm{d}$. 
Differences indicated on Table 1 show that the current sample presented higher SC scores for the following groups: men, age between 31 and 66 years old, no use of psychiatric drugs, no current engagement in paid occupancy and with offspring. The compared averages found size effects (Cohen's d), of .26 for gender differences, and between .32 and .40 for the remainder.

Correlations between total averages $(N=432)$ were all positive and significant for the three main scales $(p<.001)$. The correlation for SC and self-esteem was .47, and for SC and self-efficacy it was .50. Moreover, the correlation between self-efficacy and self-esteem was .62. Thus they are related constructs, but do not represent the same phenomenon.

Religions provided by participants on the sociodemographic survey were grouped as follows: none (no religion, atheist, skeptic, agnostic; $n=109$ ), Catholic, Protestant (Protestant, Evangelic, Lutheran, Presbyterian, Adventist, Baptist), Spirits, Buddhist, other religions (the term Christian was most used, with $n=13$, in 27 answers), and other answers (e.g., "I believe in God" and "I have an inner god"; $n=12$ ).

It is opportune to detail averages for SCS according to the four religious groups showing higher frequency for the acquired sample: Catholic $(n=186)$ with an $3.18(S D=0.73)$ average; Spiritist $(n=60)$ and $3.18(S D=0.69)$ average; Protestant $(n=30)$ and $3.09(S D=0.74)$ average; and Buddhist $(n=8)$ with the highest average, $3.32(S D=0.84)$. Averages were not compared due to the uneven distribution of participants per group. Regardless, Buddhists stood out with the highest $\mathrm{SC}$ score.

\section{Discussion}

Results show that $\mathrm{SC}$ was higher in the following groups: men, people between 31 and 66 years of age, participants not currently using psychiatric drugs, with no current engagement in paid occupancy and with offspring. Furthermore, correlations between SC, self-esteem and self-efficacy were significant, positive and with results attesting the fact they measure similar aspects, yet remain distinct constructs.

The lower SC scores on women, compared to men, detected in this study, follow the previous findings mentioned in literature (Neff, 2003b; Neff \& McGehee, 2010). This result may be connected to, as Neff (2003b) argues, the excessive self-criticism usually scored by women in this construct. Given this result, SCS's self-criticism factor was then compared by gender. $T$ testing confirmed higher selfcriticism on the feminine sample: $t(309)=1.91 ; p=.05$. Women's average was $2.77(\mathrm{~S} D=0.88 ; n=169)$ while men's was 2.96 ( $\mathrm{S} D=0.86 ; n=142)$. This difference suggests programs dedicated to promote self-compassion, when dealing with women participants, should give more attention to aspects of self-criticism, which might overcome self-kindness, sense of common humanity, mindfulness and modest levels of isolation and over-identification.

Regarding age differences and SC, this study detected a higher score for the older group. Even considering the younger group was not comprised of adolescents, who for
Neff (2003a, 2009) did not perform well in SC, the results showed a higher score for adults aged 31 to 66 years-old. Further studies with longitudinal detailing and emphasis on this issue will be needed to determine if the difference is due to developmental aspects. Neff and McGehee (2010) and Neff and Pommier (2013) did not find age differences in their studies. Still it is worthy to consider, for example, the possibility that adult life after 30 years of age presents more concurrent challenges, and as such has in its favor previous experiences that can prove useful both for the approach of new issues as well as for becoming self-compassionate in dealing with failures, sufferings and faults. Further studies, as already said, should approximate the detection of more specific aspects, in order to help elucidate the findings in differences related to age.

The other detected significant differences in averages are not sufficient to posit that having children, engaging in paid occupation or using psychiatric drugs should be aspects firmly associated with higher SC. These data were, as a matter of fact, characteristic for the current sample. Furthermore, there are no previous studies on SC using these variables.

An estimate of the benefits of parenthood, nevertheless, shows people raising children with ages up to 5 years old to have higher self-esteem, higher self-efficacy and less depression than people raising older children (Nomaguchi, 2012). In the present study, the age of children being raised was not collected, but it seems to be a relevant consideration for, at least, selfesteem levels. On account of that, given the correlations found for self-efficacy and SC, clear hypothesis could be delineated for connecting parenthood with self-compassion.

The SC concept used on this research is based on Buddhist knowledge, as explained by Neff(2003a), and we thus also sought to assess the participant's religion. Still, the very considerable size differences among groups by religion did not allow for useful average comparisons within well-grounded statistics. Nevertheless, it is interesting to take notice of SC differentiation among the groups. The Buddhist group stood out with the highest SC score, which fits the philosophical background employed by Neff (2003a) as basis for the operational definition of SC. The relationship between religiosity and psychological adjustment is attested by Gebauer, Sedikides and Neberich (2012), who verified psychological benefits (including self-esteem) for the inhabitants of countries where religiosity is more deeply valued. Of the 11 European countries studied, only Sweden showed similar scores for people who either practice or do not practice a religion. Future work should thus bring accurate data related to the relationship between $\mathrm{SC}$ and distinct religious practices.

This study is the first to correlate SC, self-esteem and general self-efficacy. The results suggest they are three different yet related constructs; ultimately they all refer to how the subject deals with his own self. The correlation found between SC and self-esteem was lower (.50) than the one detected by Vonk and Smit (2012) (.62), yet still adequate. In this way, there is support for the understanding that someone who values herself (self-esteem), that believes she can achieve her goals through her own abilities (sense of self-efficacy) and that has self-compassion - that is, reaches a wider and balanced perspective regarding thoughts 
and feelings (mindfulness) when facing sufferings, failures and errors; understands that these are part of the human experience; avoids egocentrism and the sensation of isolation from others; blocks over-identification with her own problems; reduces severe self-criticism that distorts the perspective of herself, of the world and of the future; allows self-kindness and self-acceptance as someone who also fails and errs, decreasing the emotional load of blame and other negative feelings; allows for a clearer self-image and understanding of her own difficulties (Neff, 2003a). Lastly, the only work we found that sought to correlate a self-efficacy measurement with SCS was Iskender (2009); nevertheless, only the SC dimensions were correlated, separately, with self-efficacy. It is worth noting that our research and Iskender study did not use the same self-efficacy instrument.

About our work contributions, most of all we tried to verify the relationships between SC, self-esteem and selfefficacy in literature, as well as to investigate the performance of a Brazilian sample with respect to the connections between SC and age, gender, general self-efficacy and a set of sociodemographic variables. The results were interesting particularly in relation to age and gender issues, truly accruing knowledge to the existing studies about SC.

As to the limitations of this study, firstly it is understood that the sample, even though representing a wide range of ages, was mainly with participants from the southeast and south regions of Brazil. This was the case especially due to the fact that our colleagues, who greatly helped spreading the link for data collection, mostly worked from these two regions. Secondly, as previously announced, the study was exploratory in nature, above all in considering sociodemographic variables, and dealing with almost nonexistent literature in Brazil. Therefore the results need to be contextualized on those grounds, and also the fact that it was not specifically conceived to ascertain issues of religion, paid occupation, involvement in psychotherapy and pharmacotherapy and family formation.

The Self-Compassion Scale for use in Brazil became available just as the number and acceptance of studies on mindfulness - an aspect of SC - grow in this country. Examples are the Works of Barros, Kozasa, Souza, and Ronzani (2014) and Hirayama, Milani, Rodrigues, Barros, and Alexandre (2014). Research groups in health sciences have been developing interventions using mindfulness and self-acceptance in patients with chronic diseases. The measurement of SC could be a great addition to these studies. Besides working with mindfulness and attitudes such as self-kindness, SC incorporates the perspective that suffering is a human experience, and that this way it should be understood for working against self-blaming attitudes and the feeling of being the "chosen one" while enduring some particular suffering or other. Since published research on SC is almost nonexistent in Brazil, the present work contributes Brazilian data for a construct that merits attention and research funding in this country.

\section{References}

Bandura, A. (1997). Self-efficacy: The exercise of control. New York, NY: Worth.
Barros, V. V., Kozasa, E. H., Souza, I. C. W., \& Ronzani, T. M. (2014). Validity evidence of the Brazilian version of the Five Facet Mindfulness Questionnaire (FFMQ). Psicologia: Teoria e Pesquisa, 30(3), 317-327. doi:10.1590/S0102-37722014000300009

Elkind, D. (1967). Egocentrism in adolescence. Child Development, 38(4), 1025-1034.

Gebauer, J. E., Sedikides, C., \& Neberich, W. (2012). Religiosity, social self-esteem, and psychological adjustment: On the cross-cultural specificity of the psychological benefits of religiosity. Psychological Science, 23(2), 158-160. doi:10.1177/0956797611427045

Hewitt, J. P. (2005). The social construction of self-esteem. In C. R. Snyder \& S. J. Lopez (Eds.), Handbook of positive psychology (pp. 135-147). New York, NY: Oxford University Press.

Hirayama, M. S., Milani, D., Rodrigues, R. C. M., Barros, N. F., \& Alexandre, N. M. C. (2014). A percepção de comportamentos relacionados à atenção plena e a versão brasileira do Freiburg Mindfulness Inventory [The perception of behavior related to mindfulness and the Brazilian version of the Freiburg Mindfulness Inventory]. Ciência \& Saúde Coletiva, 19(9), 3899-3914. doi:10.1590/1413-81232014199.12272013

Hutz, C. S., \& Zanon, C. (2011). Revisão da adaptação, validação e normatização da Escala de Autoestima de Rosenberg [Revision of the adaptation, validation, and normatization of the Rosenberg Self-Esteem Scale]. Avaliação Psicológica, 10(1), 41-49. Retrieved from http://pepsic.bvsalud.org/pdf/avp/v10n1/v10n1a05.pdf

Hutz, C. S., Zanon, C., \& Vazquez, A. C. (2014). Escala de Autoestima de Rosenberg [Rosenberg Self-Esteem Scale]. In C. S. Hutz (Org.), Avaliação em psicologia positiva [Assessment in Positive Psychology] (pp. 8594). Porto Alegre, RS: Artmed.

Iskender, M. (2009). The relationship between selfcompassion, self-efficacy, and control belief about learning in Turkish university students. Social Behavior and Personality, 37(5), 711-720. doi:10.2224/ sbp.2009.37.5.711

Leary, M. R., Tate, E. B., Adams, C. E., Allen, A. B., \& Hancock, J. (2007). Self-compassion and reactions to unpleasant self-relevant events: The implications of treating oneself kindly. Journal of Personality and Social Psychology, 92(5), 887-904. doi:10.1037/00223514.92.5.887

Maddux, J. E. (2002). Self-efficacy: The power of believing you can. In C. Snyder \& S. Lopez (Eds.), Handbook of positive psychology (pp. 277-287). New York, NY: Oxford University Press.

Magnusson, K. (2014). Interpreting Cohen's d effect size: An interactive visualization. Retrieved from http:// rpsychologist.com/d3/cohend/

Medeiros, H. L. V., \& Sougey, E. B. (2010). Distorções do pensamento em pacientes deprimidos: Frequência e tipos [Distortions of thinking in depressed patients: Frequency and type]. Jornal Brasileiro de Psiquiatria, 59(1), 28-33. 
doi:10.1590/S0047-20852010000100005

Neff, K. D. (2003a). Self-compassion: An alternative conceptualization of a healthy attitude toward oneself. Self and Identity, 2(2), 85-101. doi:10.1080/15298860390129863

Neff, K. D. (2003b). The development and validation of a scale to measure self-compassion. Self and Identity, 2(3), 223-250. doi:10.1080/15298860390209035

Neff, K. D. (2009). The role of self-compassion in development: A healthier way to relate to oneself. Human Development, 52(4), 211-214. doi:10.1159/000215071

Neff, K. D. (2011). Self-compassion, self-esteem, and wellbeing. Social and Personality Psychology Compass, 5(1), 1-12. doi:10.1111/j.1751-9004.2010.00330.x

Neff, K. D., \& McGehee, P. (2010). Self-compassion and psychological resilience among adolescents and young adults. Self and Identity, 9(3), 225-240. doi:10.1080/15298860902979307

Neff, K. D., \& Pommier, E. (2013). The relationship between self-compassion and other-focused concern among college undergraduates, community adults, and practicing meditators. Self and Identity, 12(2), 160-176. doi:10.1080 /15298868.2011.649546

Neff, K. D., Rude, S. S., \& Kirkpatrick, K. L. (2007). An examination of self-compassion in relation to positive psychological functioning and personality traits. Journal of Research in Personality, 41(4), 908-916. doi:10.1016/j. jrp.2006.08.002

Neff, K. D., \& Vonk, R. (2009). Self-compassion versus global self-esteem: Two different ways of relating to oneself. Journal of Personality, 77(1), 23-50. doi:10.1111/j.14676494.2008.00537.x

Nomaguchi, K. M. (2012). Parenthood and psychological well-being: Clarifying the role of child age and parentchild relationship quality. Social Science Research, 41(2), 489-498. doi:10.1016/j.ssresearch.2011.08.001

Pacico, J., Ferraz, S., \& Hutz, C. S. (2014). Autoeficácia - Yes we can! [Self-Efficacy - Yes we can!] In C. S. Hutz (Ed.), Avaliação em psicologia positiva (pp. 111-119). Porto Alegre, RS: Artmed.

Souza, L. K., \& Hutz, C. S. (in press). Adaptation of the Self-Compassion Scale for use in Brazil: Evidences of construct validity. Temas em Psicologia.

Vonk, R., \& Smit, H. (2012). Optimal self-esteem is contingent: Intrinsic versus extrinsic and upward versus downward contingencies. European Journal of Personality, 26(3), 182-193. doi:10.1002/per.817

Luciana Karine de Souza is a Professor at Universidade Federal do Rio Grande do Sul.

Claudio Simon Hutz is a Professor at Universidade Federal do Rio Grande do Sul.

Received: Mar. 30, 2015

1st Revision: Aug. 16, 2015

Approved: Sep. 9, 2015
How to cite this article:

Souza, L. K., \& Hutz, C. S. (2016). Self-compassion in relation to self-esteem, self-efficacy and demographical aspects. Paidéia (Ribeirão Preto), 26(64), 181-188. doi: 10.1590/1982-43272664201604 